\title{
Desenvolvimento de um Jogo Utilizando Robótica para o Estímulo do Pensamento Computacional
}

\author{
Rodrigo C. L. Silva, Matheus L. U. Cavalcanti, Luama R. N. L. de Oliveira \\ Instituto Federal de Educação Ciências e Tecnologia de Pernambuco (IFPE) \\ Campus Paulista - Paulista - PE - Brasil \\ rodrigo.lira@paulista.ifpe.edu.br
}

\begin{abstract}
This work presents the results of the development of a project that uses robotics to stimulate computational thinking among children from the $3 \mathrm{rd}$ to the 5th year of elementary school. The purpose of the game is to stimulate computational thinking in this age group, causing children to develop this skill that is central to current and future generations. To perform the game missions, players need to pre-define the steps (program) that the robot needs to perform to achieve the requested goal. In its initial stage, the game was developed in Scratch and will be later developed in the Arduino.
\end{abstract}

Resumo. Neste artigo é apresentado os resultados parciais do desenvolvimento de um jogo que utiliza robótica para estimular o pensamento computacional entre crianças dos 3 aos 5 anos do ensino fundamental. $O$ intuito do jogo é estimular o pensamento computacional nessa faixa etária, fazendo com que as crianças desenvolvam essa habilidade que é fundamental para as atuais e futuras gerações. Para realizar as missões do jogo, os jogadores necessitam pré-definir os movimentos (programa) que o robô precisa realizar para alcançar o objetivo solicitado. Na sua fase inicial, o jogo foi desenvolvido em Scratch e será, posteriormente, desenvolvido no ambiente de prototipação Arduino.

\section{Introdução}

O ser humano vive numa sociedade de constante transformação tecnológica onde cada vez mais conhecimento sobre tecnologia é necessário. Iniciativas como o Code.org [Code.org 2019] apresentam como o conhecimento em programação são necessários para as atuais e futuras gerações. Por isso, cada dia mais o termo "Pensamento Computacional" vem sendo difundido entre professores e pesquisadores.

De acordo com Wing (2006), o pensamento computacional amplia competências que desenvolvem e aprimoram nos alunos novas habilidades tais como: i) Pensar de forma abstrata em vários níveis e encontrar uma solução; ii) Desenvolver um produto, indo além do programa, pois é necessário pensar em diferentes níveis de abstração, permitindo o uso consciente das técnicas de programação; iii) Resolver ou desenvolver problemas com ou sem o computador; iv) Pensar ao invés de deixar que os problemas sejam resolvidos pelo computador; v) Correlacionar a área computacional com a matemática e as engenharias.

O pensamento computacional é uma habilidade fundamental para todos, não somente para cientistas da computação. Por esse motivo, nos últimos anos, vários países, incluindo EUA [Obama White House 2019] e Reino Unido [Guardian 2019], 
incentivaram a adição desses conceitos no currículo escolar para ajudar a criar uma nova geração de "Mark Zuckerberg's". Nesse sentido, a Sociedade Brasileira de Computação (SBC) apresentou, para ser incluída na Base Nacional Comum Curricular (BNCC), proposta que se baseou em destacar a importância desse conhecimento para os estudantes serem capazes de solucionar desafios cotidianos [Fundação Telefônica Vivo e Fundação Lemann 2018].

Com o intuito de estimular o esse tipo de pensamento, este artigo irá apresentar os primeiros resultados do desenvolvimento de um jogo utilizando robótica educacional para estímulo do pensamento computacional. Nele, os jogadores precisaram utilizar conceitos de lógica de programação para poder controlar a movimentação de um robô em um mapa que será o tabuleiro do jogo. Ao final, espera-se criar uma solução semelhante ao Cubetto da empresa PrimoToys [Primotoys 2019] com um custo mais acessível e que se adeque a realidade de ensino brasileiro.

Esse artigo está dividido da seguinte forma: na Seção 2 são apresentados os trabalhos relacionados. Na Seção 3 é apresentado a metodologia da construção do jogo. $\mathrm{Na}$ Seção 4 é apresentado a descrição do jogo. Na Seção 5 são apresentados os resultados parciais do desenvolvimento do jogo, e por fim, na Seção 6, é apresentado a conclusão do artigo.

\section{Fundamentação Teórica}

Gomes et al. (2016) relataram a experiência do ensino de programação utilizando jogos digitais para um grupo de crianças entre cinco e seis anos de uma escola. Neste trabalho os autores utilizaram os jogos: Code Baymax, Code Monkey, Code Studio, Lighbot, Ninja Shape e o The Foos. Os resultados obtidos sugeriram que os jogos eram uma forma de apoiar o ensino de programação para a faixa etária estudada por proverem uma abordagem lúdica. No entanto, os autores perceberam que a interface dos jogos não levava em consideração especificidades do público da experiência.

Martins et al. (2016) apresentaram os resultados de uma ação onde os alunos do curso técnico do IFAM Campus Parintins auxiliaram os alunos do $5^{\circ}, 6^{\circ}$ e $7^{\circ}$ ano de uma escola aplicando e ensinando noções básicas de lógica, algoritmo e programação, por meio do site Racha Cuca, a ferramenta Scratch e o Lego Mindstorm ${ }^{\circledR}$ Education EV3. Os autores relataram que de forma geral, os alunos começaram a despertar interesse pela área de tecnologia da informação.

Santos et al. (2018) apresentaram uma investigação sobre o ensino de programação e de princípios da robótica no Ensino Fundamental. O projeto concentrouse em ensinar conceitos de robótica a crianças que estão na fase de alfabetização. Para esse objetivo foi construído um carrinho-robô com sensores de distâncias. O robô foi criado utilizando o kit de robótica AttoBox e foi programado para criar uma aula mais interativa. Os alunos foram apresentados ao robô e incentivados a criar seus próprios códigos nas plataformas ArduBlock e Scratch, onde controlaram um carro virtual. Com isso, o projeto buscou mostrar como o ensino de programação e de robótica pode ser inserido, por meio de sequências didáticas, no ciclo de alfabetização.

\section{Metodologia}

O jogo proposto neste trabalho está sendo desenvolvido em duas plataformas. No primeiro momento será construído em plataforma digital, usando a ferramenta Scratch, e em seguida, fabricado utilizando a plataforma de prototipação Arduino.

Para a criação do jogo digital foi escolhido a plataforma Scratch do MIT pela sua facilidade de criação de animações e jogos. Esse ambiente será um local onde os jogadores poderão se familiarizar com o jogo, além de ser uma oportunidade dos 
criadores provarem conceitos que serão desenvolvidos com o Arduino.

Antes da sua montagem em plataforma Arduino, o sistema será testado no Tinkercard [Tinkercard 2019] para simular os dispositivos utilizados, com o intuito de encontrar falhas que não foram vistos na fase de concepção e permitindo que erros de projetos sejam descobertos antes da montagem

O chassi do robô foi baseado no projeto do Otto with wheels (Otto com rodas) (Figura 1) que está disponível no site Thingverse [Thingiverse 2019]. Ele consiste de um robô que pode ser impresso com uma impressora $3 \mathrm{~d}$, em que as suas rodas são acionadas através de servomotores e o seu controle é feito através de um microcontrolador.

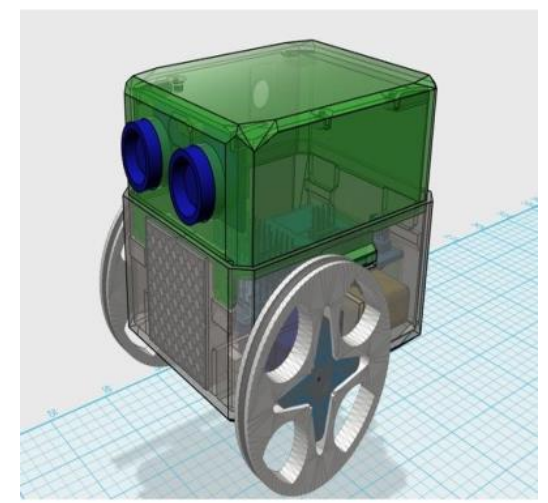

Figura 1. Projeto em 3d do robô Otto que será utilizado na confecção do jogo. Fonte: Thingverse

O mapa ou o tabuleiro do jogo será confeccionado em formato de banners para facilitar o transporte a criação de novos cenários. Os cenários serão definidos na fase de implementação e apresentarão imagens lúdicas que estimulem os jogadores.

\section{O Jogo}

O jogo foi idealizado para realizar o desenvolvimento do pensamento computacional através da apresentação de conceitos simples de lógica de programação. Seu públicoalvo são crianças do $3^{\circ}$ e $5^{\circ}$ anos do ensino fundamental dos anos iniciais, mas nada impede sua utilização em outras idades que queiram ter esse contato com lógica de programação. Como se trata de uma ferramenta que aborda comandos de programação simples, servirá para a introdução à programação, integrada a conteúdos curriculares de quaisquer disciplinas.

\subsection{Jogabilidade}

O objetivo do jogo é fazer com que o robô controlado pelo jogador realize os movimentos necessários para completar a missão definida na rodada. Cada missão estará diretamente relacionada ao tabuleiro (mapa) utilizado na rodada. Dependendo do mapa, as missões podem envolver conhecimentos de matemática, inglês, português, etc. Na Figura 2 é apresentado um protótipo de tela do jogo. Nesse mapa, o jogador precisará ter conhecimentos das letras do alfabeto para conseguir alcançar o objetivo.
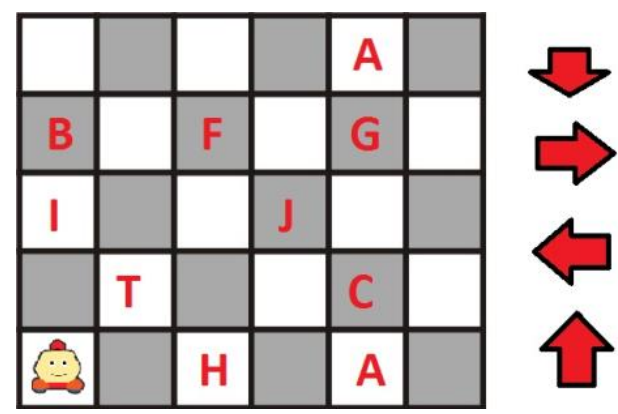
Figura 2. Protótipo de tela que utiliza um mapa com informações das letras do alfabeto. Fonte:

Próprio Autor

Os exemplos de missões que podem ser estabelecidas no mapa anterior são: "Percorra todas as vogais do mapa e volte para o início", "Encontre a terceira letra do alfabeto", "Percorra em ordem as letras que formam a palavra CHÁ", etc. Em outros mapas, podem ser requisitados conhecimentos diferentes, como: "Encontre a capital do estado de Pernambuco?", "Encontre a tradução da palavra inglesa house?" e o jogador terá que responder com os comandos: direita, frente, esquerda e abaixo necessários para o robô chegar até a resposta. Em cada uma dessas missões a forma de resolução é a mesma, o jogador deve movimentar o robô até a resposta da missão utilizando os recursos de movimentação disponível no jogo.

Para realizar as missões, os jogadores necessitam pré-definir os movimentos (programa) que o robô precisa realizar para alcançar o objetivo solicitado. Além disso, eles terão que relembrar os conhecimentos adquiridos nas respectivas matérias envolvidas.

\section{Resultados Parciais}

O projeto encontra-se na fase final do desenvolvimento do jogo digital. Nos próximos parágrafos será descrito os resultados alcançados nessa fase de desenvolvimento que precede a fabricação do robô físico.

O jogo digital possui a seguinte jogabilidade: ao iniciá-lo, o jogador é apresentado a tela de escolha de mapa (Figura 3). Nela é possível escolher entre o Mapa 1 (Figura 4a), Mapa 2 (Figura 4b) e Mapa 3 (Figura 5).

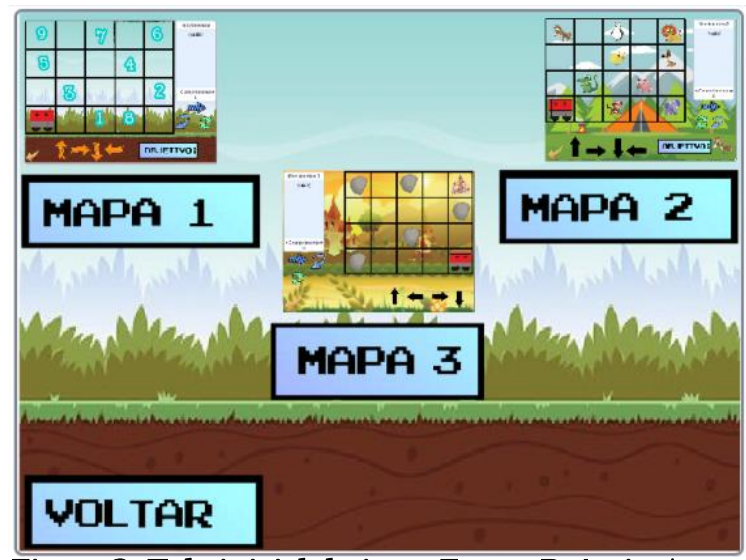

Figura 3. Tela inicial do jogo. Fonte: Próprio Autor

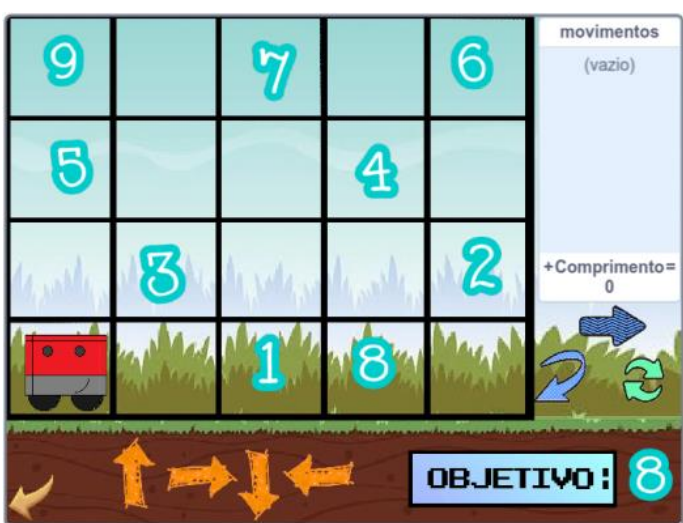

(a) Mapa 1

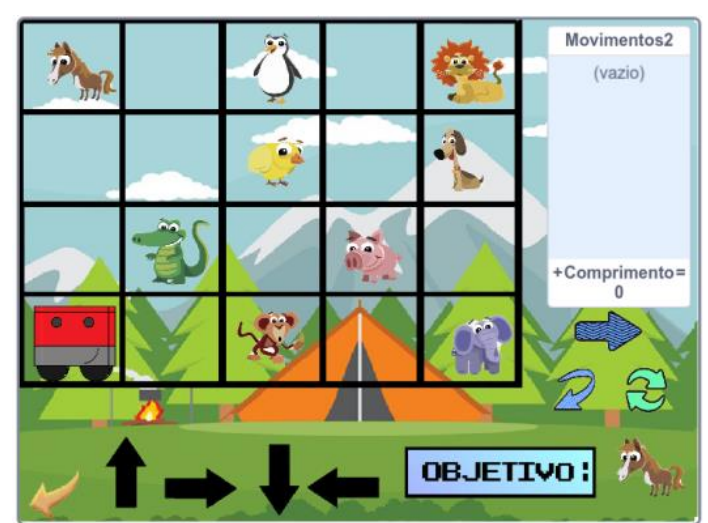

(b) Mapa 2

Figura 4. Mapas desenvolvidos para o jogo educacional. Fonte: Próprio Autor

Após a escolha do mapa, o jogo sorteia aleatoriamente um objetivo que deve ser 
alcançado com a movimentação do personagem. Os objetivos de cada mapa são diferentes, no Mapa 1 o jogador deve movimentar o personagem até o número sorteado, enquanto que no Mapa 2 o movimento deve ser realizado até o animal sorteado. No Mapa 3 são adicionados obstáculos ao longo do cenário do mapa. Nele, o personagem precisa se movimentar até o castelo que é colocado em uma posição aleatória do mapa a cada rodada.

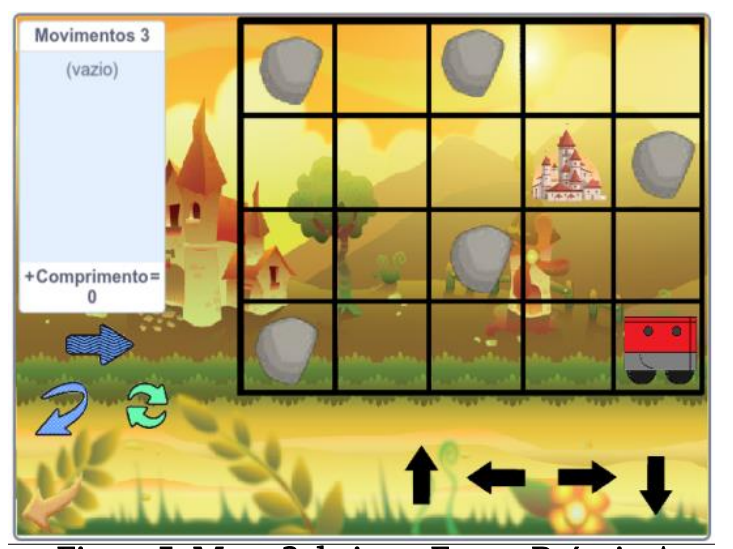

Figura 5. Mapa 3 do jogo. Fonte: Próprio Autor.

Em cada mapa, se for alcançado o objetivo, o personagem parabeniza o jogador e uma nova rodada se inicia (Figura 6a). Caso o jogador erre os movimentos necessários para alcançar o objetivo, o personagem lhe informa que o objetivo não foi alcançado e pede para ele tentar novamente (Figura 6b).

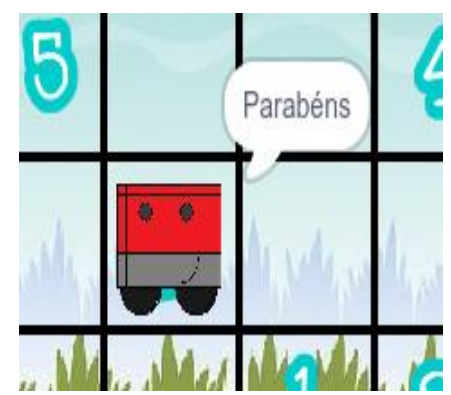

(a)

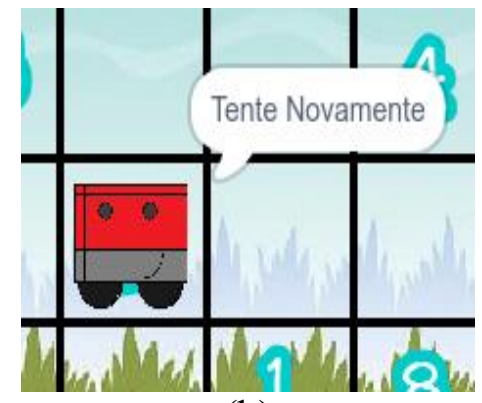

(b)

Figura 6. Informações após o fim da rodada. Fonte: Próprio Autor

Além dos comandos para a movimentação do robô, o jogador pode sair do mapa, iniciar a movimentação do robô ou apagar a última movimentação escolhida através de opções apresentadas na tela do jogo (Figura 7).

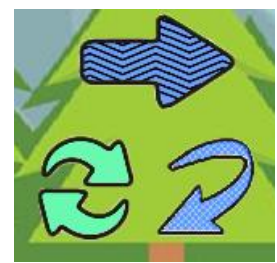

Figura 7. Ações disponiveis ao jogador. Fonte: Próprio Autor

\section{Conclusão}

Neste artigo foi apresentado o projeto de um jogo que para estímulo do pensamento computacional utilizando robótica educacional. O jogo foi desenvolvido em plataforma digital utilizando o Scratch e será desenvolvido de forma física utilizando Arduino e um chassi impresso em impressora $3 \mathrm{~d}$. 
O objetivo do jogo é fazer com que o jogador movimente o robô ao local indicado no início de cada rodada. Para alcançar esse objetivo, o jogador precisa programar as movimentações (cima, baixo, direita e esquerda) corretas no robô. No momento, os autores estão finalizando o desenvolvimento do jogo digital para em seguida iniciar a fabricação do robô utilizando a plataforma Arduino.

Após a fase de desenvolvimento do projeto, espera-se criar oficinas na comunidade interna e externas do campus. Nessas oficinas serão utilizados os dois produtos, o jogo digital e robô educacional para estimular o pensamento computacional. A expectativa é que esse tipo de exercício estimulem as crianças a pensarem de forma lógica. Com isso espera-se despertar o interesse das crianças e adultos para a área de computação e apresentar de forma divertida os conceitos de programação.

\section{Referências}

Code.org. Site do code.org. Disponível em: https://code.org/. Último acesso: maio de 2019.

da S. Martins, L. A., da S. Brelaz, A., Nascimento, G. R., Alfaia, R. M., and dos S. Martins, T. (2016). Ensinando lógica de programação aplicada à robótica para alunos do ensino fundamental. Anais do SBIE 2016 (Proceedings of the SBIE 2016), pp. 31- 41, 2016.

dos Santos, L. M., Basso, S. J. L., Freitas, L. K. M., and Tieppo, T. A. M.. Ensinando programação e robótica para o ensino fundamental. Anais do III Congresso sobre Tecnologia na Educação (Ctrl+E 2018), pp. 314-322, 2018.

Fundação Telefônica Vivo e Fundação Lemann. Programaê: Um guia para construção do pensamento computacional. 1 ed. 2018.

Gomes, T. C. S., de Melo, J. C. B., and Tedesco, P. C. A. R. Jogos digitais no ensino de conceitos de programação para crianças. Anais do SBIE 2016 (Proceedings of the SBIE 2016), pp. 470-479, 2016.

Guardian, T. Coding at school: a parent's guide to england's new computing curriculum. Disponível em: https:/www.theguardian.com/technology/2014/ sep/04/coding-school-computing-children-programming. Último acesso: abril de 2019.

Obama White House. Computer Science for all. Disponível em: https://obamawhitehouse.archives.gov/blog/2016/01/30/computer-science-all Último acesso: abril de 2019.

Primotoys. Site do primotoys. Disponível em: https://www.primotoys.com/. Último acesso: maio de 2019.

Thingiverse. Thingiverse otto with wheels. Disponível em: https://www. thingiverse.com/thing:2503709. Último acesso: maio de 2019.

Tinkercad. Site do AutoDesk Tinkercad. Disponível em: https://www.tinkercad.com/ . Último acesso: agosto de 2019.

Wing, J. M. Computational thinking. Commun of the ACM, ed. 49; n. 3. pp. 33-35, 2006. 